\title{
"It's Broader than Just My Work Here": Gender Variations in Accounts of Success among Engineers in U.S. Academia
}

\author{
Dilshani Sarathchandra ${ }^{1, *}$, Kristin Haltinner ${ }^{1}$, Nicole Lichtenberg ${ }^{2}$ and Hailee Tracy ${ }^{1}$ \\ 1 Department of Sociology \& Anthropology, University of Idaho, Moscow, ID 83844, USA; \\ khaltinner@uidaho.edu (K.H.); trac7345@vandals.uidaho.edu (H.T.) \\ 2 The Community Library Association, Inc., Ketchum, ID 83340, USA; nicolezlichtenberg@gmail.com \\ * Correspondence: dilshanis@uidaho.edu; Tel.: +1-208-885-6664
}

Received: 10 December 2017; Accepted: 25 February 2018; Published: 28 February 2018

\begin{abstract}
Among science, technology, engineering, and math (STEM) disciplines, the percentage participation of women in engineering has shown significant gains over the past few decades. However, women are still largely absent (or exist in very small numbers) in tenured academic ranks in several engineering sub-fields. In this study we present female and male engineers' varying understandings of 'scientific success' as a potential contributor to women's retention and success in their (sub)fields. Using in-depth interviews conducted among engineering graduate students and faculty at two U.S. Northwest land-grant research universities, this study demonstrates the 'dual' nature in accounts of scientific success, where formal measures of success operate in tandem with informal measures. While both men and women attribute their success to formal and informal measures, gender-based variations tend to be more prevalent among informal measures. By examining these informal measures, this study highlights the context surrounding success.
\end{abstract}

Keywords: gender; engineering; scientists; STEM; women in engineering

\section{Introduction}

Affirming the strong case laid by Shiela Widnall in her 1988 AAAS Presidential Lecture: "Voices from the Pipeline" (Widnall 1988), that brought gender disparities in science into the spotlight, social scientists have long engaged in empirical investigations on women's underrepresentation in science, technology, engineering, and math (STEM). Much of this research in the United States has focused on delineating factors that contribute to underrepresentation, including potential biological explanations, social psychological factors (e.g., stereotype threat, chilly climate), and cultural/institutional barriers (e.g., lack of positive experiences with science, lack of academic preparation for STEM majors and careers, absence of female scientists or engineers as potential role models, and cultural pressures on girls and women to conform to traditional gender roles) (Blickenstaff 2005; Ceci et al. 2014; Beyer 2015).

Over the past few decades, while the percentage participation of women in life science, psychology, and social science, at bachelors, $\mathrm{PhDs}$, and assistant professor levels has improved, in math-intensive disciplines scholars have noted variable gains in the pipeline. For instance, while the number of bachelor's degrees awarded to women in some math-intensive disciplines such as geoscience, physical sciences, and engineering have "more than doubled since the 1970s" (Ceci et al. 2014, p. 78), in other areas such as mathematics and computer science, the numbers have experienced a decline (Ceci et al. 2014).

Among math-intensive STEM disciplines, engineering has shown significant growth, both in terms of the proportion of women who obtain PhDs, and the proportion of women who choose academic 
careers. Among tenure-track assistant professor ranks in math-intensive STEM disciplines in the United States, engineering has grown from "nearly 0\% female in 1973 to 30\% in 2010" (Ceci et al. 2014, p. 80). While this is an extremely positive trend, these numbers fail to capture the entire picture of gender (in)equity in engineering. Women still lag behind in tenured academic positions: only $16.3 \%$ of tenured engineering faculty are women (Yoder 2017). To achieve equitable female representation in tenured associate and full professor levels, similar growth rates must be sustained through the process of promotion and tenure.

Building on extant scholarship on the STEM gender gap, we investigate scientists' own understandings of what shapes successful STEM academic careers, as a potential factor to shed light on the gender gap. In particular, we seek to understand how scientists in a traditionally male-dominated scientific field (i.e., engineering) describe and interpret their success. What criteria do they use to explain success for themselves and for the scientific community? Are there gender variations in how male and female engineers describe their success? Gender variations in accounts of success may carry potential implications for female engineers' retention in engineering academia. As an integral component of 'gender performance' in the workplace (Ridgeway 1997), descriptions of success may help reduce or exacerbate existing inequalities between the sexes (Gherardi 1994).

Our results are based on a set of in-depth interviews conducted among academic engineers at two land-grant research universities in the U.S. Northwest. While traditional accounts of success often refer to easily quantifiable formal measures such as number of publications and citations, grants, awards, patents, and the like, in engineering academics' accounts of success, we encountered criteria that are typically shelved away under the extrinsic, non-quantifiable, and/or contextual. These "informal" measures of success, which often elude bibliometric analysis, still carry implications for retention and advancement of women, especially in male-dominated spaces. They explicate variations in how male and female academics reflect and act upon their professional success.

\section{Relevant Literature}

\subsection{Women in Engineering}

Extant social science scholarship consists of ample evidence for barriers faced by women seeking to enter traditionally male-dominated educational and work environments. Women are often seen as 'unfeminine' when performing tasks competently (Gherardi 1994; Evetts 1997). They are also categorized as either 'honorary men' or 'flawed women' when participating in male-dominated fields (Etzkowitz et al. 2000). Furthermore, studies show that women in male-dominated industries "either have to act like men in order to be successful, leave if they are not adaptable to the culture, or remain in the industry without behaving like men but maintaining unimportant positions" (Powell et al. 2009, p. 412). When 'fitting in' to the majority culture, women are often caricaturized into token positions such as the 'caring mother.' Specifically for engineering, Powell et al. (2009, p. 424) research posits that women engineers are caught in a double bind where, "they can choose to be accepted, for example by acting like 'one of the lads', but simultaneously deny their gender, or choose not to be accepted at all."

In male-dominated scientific fields, women scientists use various coping mechanisms such as 'distancing,' a strategy Rhoton (2011) describes as creating a boundary between themselves and non-STEM women faculty, STEM women faculty, or women in general. Women 'distance' in many ways, including by essentializing gender stereotypes (e.g., 'women are emotional and passive-aggressive') while asserting that these instincts can be quelled (because they themselves are not emotional). Distancing also involves accepting one's own experiences of gender discrimination as an individual problem rather than a systemic issue (Rhoton 2011). For example, Erickson (2012) found that women Ph.D. students, while unwilling to describe instances of gender bias in their own lives, willingly describe these biases in the lives of other female students.

In spite of these barriers, and the general lack of women in some STEM disciplines, women have demonstrated relatively higher participation in academic engineering over time (Ceci et al. 2014, 
p. 80). The increased participation is caused by women entering science and engineering tracks for the first time in college and by some engineering sub-fields becoming more welcoming to women (e.g., environmental engineering). Overall however, in academia and in industry, women are still a minority.

Empirical evidence shows that factors such as lack of female mentorship, differences in early gender socialization, 'chilly climate' in academia/workplace, and other cultural as well as structural barriers (Dryburgh 1999; Blickenstaff 2005) keep women from entering male-dominated fields. Furthermore, the cultural ethos (and images) of engineering as a predominantly masculine discipline may reinforce the perception that engineering is unsuitable for women (Evetts 1998) and compel women to either actively choose not to enter engineering careers (Glover et al. 1996), or suffer negative consequences when entering these careers and attempting to defy cultural dictates (Evetts 1998). Overall, these challenges are rooted in a general cultural ethos where masculinity is treated as superior to femininity.

In the highly masculine engineering culture, women use various strategies for managing tensions, including uncritically accepting masculine cultural norms, and working hard to show solidarity with their male colleagues (Dryburgh 1999; Powell et al. 2009, p. 413). In male-dominated environments, women are often made to 'fit in' and be accepted by implicitly devaluing their 'femaleness.' For example, in a study of women engineering students, Powell et al. (2009) show that women's enculturation into engineering results in their "doing gender in a particular way"; by acting like one of the boys, accepting and normalizing gender discrimination, seeing advantages over disadvantages, achieving a reputation as a scholar, and adopting an 'anti-woman' approach. Because these actions simultaneously result in women's implicit and explicit devaluation, "in 'doing' engineering, women often 'undo' their gender" (Powell et al. 2009, p. 411), and fail to challenge the prevailing gendered culture (Powell et al. 2009).

In ethnographic fieldwork conducted in three companies, Faulkner $(2009$, p. 15) further examines the impacts of "subtle 'taken-for-granted' gender dynamics in engineering workplace cultures" and identifies a mixed picture of inclusivity and exclusivity for women in engineering. Women in this study reported experiencing generally respectful styles of interaction with their male colleagues, and opportunities for 'mixed-sex' social networking, but they were also subjected to conversations "dominated by men's interests" and the "generic he." Overall, engineering cultures in both academia and industry seem to favor men's membership more than women's.

Moreover, as women migrate to interdisciplinary research in academia, they seem to grapple with a preexisting hierarchy that favors the success of male engineers. The expectation of gender-based differences in thinking and learning styles seems to be "gendering" interdisciplinary; women find more success in fields such as environmental engineering that are seen as having "a positive impact on society" and align with "women's higher concern for adverse environmental and health impacts of scientific policies and applications than men" (Rhoten and Pfirman 2007, p. 67). The finding about environmental engineering aligns with much of the prior research on gender-preferences, which suggests that women are more likely to choose branches of science oriented towards applicability and needs (e.g., social sciences, law, and medicine) (Keller 1985; Farrell 2002; Rhoten and Pfirman 2007). However, these perceptions further reify gendered expectations of women as forebears of concern for societal wellbeing.

Barriers women engineers face in interdisciplinary research seem to extend to international collaboration as well. As such, while the frequency of international research collaborations vary by the region, U.S. women engineers are more likely to report no prior international collaborations, in comparison to those in Europe and those outside of U.S. and Europe. Women engineers have pointed to two particular barriers to seeking international collaboration: finding suitable collaborators and lack of funding for research (Fox et al. 2016). 


\subsection{Measures of Scientific Success}

Factors that contribute to success in academia are varied and depend on the institution as well as the discipline under consideration. General criteria include exhibiting productivity through publications, citations, and grants, gaining visibility within the scientific community, and achieving promotions. Productivity, often measured through publications and citations, is strongly linked to a scientist's overall visibility within the scientific community (Long et al. 1993). Furthermore, promotions, often achieved through higher visibility (Leahey 2007), are essential within academia, which allows for rank advancement and further autonomy over research ideas and teaching programs. As such, productivity, visibility, and promotion seem to go hand in hand in typical accounts of scientific success.

Sociological examinations of scientific success have taken three main approaches, according to Leahey and Cain (2013): (1) Mertonian sociology of science that explicates correlates and determinants of success (Long et al. 1993; Leahey 2007), (2) scientific ethnographies that examine scientists' own perspectives about their success (Latour 1987), and (3) historical comparative analysis that focuses on in-depth analysis of small numbers of determinants, such as adaptability of work, mentoring relationships, and other professional relationships. Beyond these approaches, Leahey and Cain (2013, p. 928) posit that "our understanding of scientific success is also informed by folklore," which includes cultural notions of scientists and scientific work (e.g., 'lone scientists' 'men of science' 'scientific breakthroughs').

Arguing that the above methods do not develop a comprehensive picture of scientific success, Leahey and Cain (2013, p. 929) introduced a method of analysis that relies on scientists' personal reflections of success as revealed in essays written by highly cited scientists in Citation Classic essays. This research has uncovered various "hidden factors" that are "only recognizable by the scientists themselves - such as the ubiquity of frustration and the helpfulness of friends." As such, Leahey and Cain argue that paying close attention to hidden factors in scientists' accounts of success can lead to a more nuanced understanding of "not just scientific success but the cultural context surrounding it." While Leahey and Cain (2013) analysis lays an important foundation for exploring various (sometimes hidden) facets in scientific success stories, our research focuses on exemplifying potential gender variations in those, by examining a specific population of academic scientists-scientists in engineering, a traditionally male-dominated discipline.

\subsection{Other Barriers to Achieving Success in STEM}

From prior research we know that women face a multitude of challenges when trying to achieve success in STEM academia. Some challenges are related to structural barriers, while others result from subtle cultural expectations of appropriate behavior for women (and men) (Blickenstaff 2005), such as the expectation (and evidence from time allocation studies) that women place more emphasis on mentoring relationships and service than men (Link et al. 2008).

Women's productivity often differs when personal relationships (marriage, family, children) collide with professional relationships (Long 1990; Fox 2005). For instance, Long (1990) found that married women are more likely to have educational interruptions which can delay success, while Fox (2005, p. 146) posited that, when accounting for type of marriage, occupation of the spouse, and family composition, neither marriage nor having children necessarily depress publication productivity: women in subsequent marriages usually have higher productivity than women in first marriages (due to their greater likelihood of being married to another scientist) and women with preschool children show higher productivity compared to women without children or women with school-age children. Furthermore, female scientists' low publication rates in comparison to their male counterparts can often be explained by other structural and contextual factors such as the type of institution, availability of funding, and time to Ph.D. (Xie and Shauman 1998, 2003; Ceci and Williams 2011).

In a recent study, Tao et al. (2017) did not observe a statistically significant productivity gap in engineering, nonetheless, "women engineers are highly concentrated at the rank of assistant professor." 
This paradox indicates that women are still disadvantaged in this field (Tao et al. 2017, p. 18). All in all, with factors that can delay scientific success stacked against women, "it often takes a longer period of time and a greater number of publications for women to be recognized as meriting promotion or senior status, than for their male peers" (Rhoten and Pfirman 2007, p. 68), which can further hinder women's retention and success in STEM and male-dominated academic fields.

\section{Data and Methods}

This study draws from 23 in-depth interviews conducted among engineering graduate students and academics at two land-grant research universities in the U.S. northwest. Interviews were conducted during the 2014/15 academic year by a team of four researchers. IRB approval from the authors' university was obtained prior to initiating data collection.

Following Xie and Killewald (2012, p. 9), we used an 'education-based definition' to identify individuals for the study and considered both individuals working with or working toward engineering advanced degrees as potential interviewees. Subjects were recruited using a purposive sampling technique to (a) oversample women, (b) cover a broad range of engineering sub-fields and career trajectories, and (c) reflect all levels of academic promotions. Thus, our sample included full professors, associate professors, assistant professors, post-doctoral scholars as well as graduate students (Table 1). Twelve of the participants were female and 11 were male. Participants represented several sub-fields: electrical engineering, chemical engineering, computer engineering, biosystems engineering, mechanical engineering, environmental engineering, and civil engineering.

Table 1. Interview sample; by academic position and gender (Total $\mathrm{N}=23$ ).

\begin{tabular}{ccc}
\hline Academic Position & Female & Male \\
\hline Professor & 2 & 2 \\
Associate professor & 2 & 1 \\
Assistant professor & 1 & 2 \\
Postdoctoral scholar & 1 & 3 \\
Graduate student-Ph.D. stream & 3 & 3 \\
Graduate student-MS stream & 3 & 1 \\
Total & 12 & 11 \\
\hline
\end{tabular}

We interviewed each participant individually using a semi-structured interview guide (see Appendix A). Each interview lasted approximately one hour (ranging from $45 \mathrm{~min}$ to $1.5 \mathrm{~h}$ ). The questions were open-ended and were used to elicit participants' views and experiences related to their research foci, interests, goals, and measurements of successes and failures. We began the interviews with questions about participants' selection of research projects, their relationships with other scientists and collaborators, and the daily workings of their research laboratories. We then asked participants to discuss how they select and pursue their research agendas and elaborate on their perceptions about the strengths, successes and shortcomings of their research. Subsequently, we asked general questions about professional and personal goal setting and criteria participants use to determine whether they have reached their desired goals and levels of success.

All interviews were recorded with participants' consent and transcribed verbatim. All identification information other than gender, academic rank, and engineering sub-field were removed from the transcriptions. The data analysis used standard inductive analysis (Silverman 2004), and emphasized the identification of definitions, key categories, themes, narratives, and expressive devices. The initial codebook was developed by three members of the research team, each independently coding a sample of 5 interview transcripts. To ensure inter-coder reliability, coding scheme/example quotes for all interviews were crosschecked by at least two members of the research team. The focus of the results includes how participants describe and reflect on their professional goals and successes within their work environments, in tandem with their personal goals. Because interview data generally consists 
of retrospective rationalizations, we can assume that our data reflects interviewees' attitudes and perceptions, as well as their understandings of norms that govern what 'should' count as success in their chosen disciplines.

While our purposive sample may not be representative of female and male engineering academics (and we do not intend to make claims for generalizability of our findings), the range in terms of academic ranks and sub-fields, as well as the number of interviews with both men and women, is broad enough to indicate their experiences (Table 1). Our interview sample consists of at least one male and one female participant in each rank, which is especially pertinent when considering the dearth of women in tenured academic ranks in engineering. Because our interview data consists of both male and female engineers (as opposed to studies that have exclusively focused on women engineers; e.g., (Powell et al. 2009; Fox et al. 2016)) we are able to explore how both groups engage in gender performance and construct themselves within male-dominated spaces. Furthermore, we suggest that qualitative findings such as those presented in this research could illuminate the rich extant literature on gender and STEM, which typically leans towards uncovering trends through quantitative methods.

\section{Results and Discussion}

\subsection{Formal Measures in Accounts of Success}

In areas that are formalized through institutional expectations, such as evaluation criteria for research and teaching assistantships, tenure, and promotion, both male and female graduate students and academics described similar measures of success (Table 2, column 1). All participants gave credence to publications, citations, publication venue, and recognition through grants and awards. Several of the respondents also mentioned replication and validation of results as an important criterion for success, which affirms Leahey and Cain (2013, p. 930) categorization of replication, validation, and confirmation as the "scientific gold standard." Other institutional correlates mentioned in the interviews included co-authorship and collaboration, design outputs, commercialization, and patents. As one female associate professor summarized: "It all comes down to papers, grants, and to some extent, being known in the field" (Female associate professor 2). These perceptions are also common among graduate students: "I would say generally in the chemical engineering field you want to be well known, well networked, well-funded with research dollars and also known in your field" (Female Ph.D. candidate 1).

Both faculty and Ph.D. students also mentioned measures of teaching excellence and graduate student training (for faculty), as contributory factors to their success, although typically, teaching accomplishments were mentioned as secondary to scholarship. Typical descriptions of the relative weight given to teaching and research include:

The typical goals for my field are publish, publish, publish. Develop a name and reputation. Finances are useful but not critical. Although the bigger schools tend to pay better. First and foremost publish. Secondly, being a good teacher. Being able to relate to students, because if you're not a good teacher your horizons are limited. (Male Ph.D. candidate 2)

Primarily the number of research publications followed by teaching evaluations. And if you do those well, if you do those two things well, the rest of the stuff helps, but those are the primary criteria. (Male Ph.D. candidate 1)

So, it is basically the number of papers, the number of grants, and number of grad students. Not so much the number of dollars, but, that's part of it too because with more dollars you can have more number of students, more papers, it is just sort of a thing. (Male professor 2)

Due to the institutional guidelines for funding, tenure, and promotion set by of the universities where this research was conducted (i.e., two land-grant research universities), the relative value participants place on teaching and research is not surprising. Land-grant universities in the United 
States are established on a three-fold mission of teaching, research, and outreach (Schuh 1986), which codifies criteria for measuring how individuals and research groups contribute to accomplishing institutional goals. Although the land-grant mission entail outreach and engagement with communities (McDowell 2003), our respondents only rarely mentioned this as critical to their scientific success (hence our categorization of 'ability to help people and communities' as an informal measure).

Both engineering faculty and students in our sample recognize that the above criteria are formalized through prevailing scientific norms and practices as well as institutional mandates. They expressed that these criteria are systematized, often in measurable ways, to support institutional assessments of success:

Okay, well the easy answer is it's kind of the cumulative track record or an upward trend of activities and accomplishments. Accomplishments have to be documented. Activities are just sort of the necessary things that you do that do not get any kind of documented thing for. (Male professor 2)

There have been guidelines established and provided to us in terms of what our teaching expectations are and by teaching expectations it is really the teaching evaluations and feedback provided by students. There is a baseline expectation that we will provide the material to the students and it will be conveyed in an effective manner. So, there's the teaching component. There is also an expectation to conduct research and publish the results of that research. And then thirdly, an expectation to bring in funding, primarily grant funding to support both the research as well as being able to support some students down the road. (Female associate professor 1)

Table 2. Formal and informal measures in accounts of scientific success.

\begin{tabular}{cc}
\hline Formal Measures & Informal Measures \\
\hline $\begin{array}{c}\text { Publications, citations, publication venue } \\
\text { Collaborations, co-authorships } \\
\text { Grants, contracts, external funding }\end{array}$ & $\begin{array}{c}\text { Ability to help people and communities } \\
\text { Mentoring relationships (as mentor and mentee) } \\
\text { Personal relationships, family support }\end{array}$ \\
\hline Reputation, recognition, awards & Happiness \\
\hline Graduate student training, placement & Satisfaction from research \\
\hline Teaching excellence & Failure as a form of success \\
\hline Products, design outputs & Overcoming personal struggles \\
\hline Commercialization, patents, utility & Maintaining quality of life \\
\hline Replication, validation & Ability to handle stress \\
Breakthrough research & Risk taking \\
Results 'standing the test of time' & Competitiveness
\end{tabular}

\subsection{Informal Measures in Accounts of Success}

In addition to the above formal measures of success, participants expressed that they evaluate their success along a set of informal measures (Table 2, column 2). As such, the ability to help people and communities through research, maintaining satisfactory personal and professional relationships, achieving happiness and satisfaction through one's work and in one's work environment, and being able to overcome personal struggles were also mentioned as measures of success. Additionally, several of our respondents identified the ability to handle stress and failure as a form of success, which we turn to in the below sections.

A typical description of success, for both male and female engineering academics and graduates, included a conjunction of formal and informal measures. Below, we see a respondent engaging in this "dual" accounting, on the one hand referring to formal assessment criteria, and on the other, referring 
to informal measures-'joy and happiness' in this particular case- that capture causes and outcomes of success.

I got tenure at a research university, you could consider that as a level of success. There are some publications that I thought were pretty good, that have not been cited much. Although I think they are good, my community of fellow researchers have not determined them to be good enough. To me, in the position I am at right now, success is doing what I like to do, and publishing work that I think is good. Even if a lot of people don't cite it, if it is something that brings me joy and happiness, and I am ok with it. (Male professor 1)

Notably, it is in the descriptions of informal measures that we began to observe gender-based variations more clearly, as discussed in the next two sections. Specifically, we find both men and women mentioning the importance of relationships, though in different ways. We also find the prevalence of gender-based stereotypes affecting one's perceptions of success, along with the sense that one's success is broader than just 'measurable' accomplishments:

In general, I can think of a lot of women who have similar definitions of success as I do, but I also have, I feel like it's broader than just my work here ... For some people it might be research, having a big lab, having a lot of grants, having a lot of papers. I guess my definition of success might be not that far off. Or, maybe I'm not as successful as other people. I guess that's it... People looking at things like grants or papers or that type of thing, probably would not view me as successful. (Female associate professor 1)

\subsubsection{Differing Conceptualizations of Relationships}

While both men and women mentioned relationships, they differed in the way they conceptualized, or understood, relationships. Women engineers were more likely to mention mentoring relationships, both as mentees and mentors, in their accounts of success, while male faculty members were more likely to describe graduate student mentoring as a transactional relationship (e.g., "how many students you graduate" (male full professor 2)). Women were also more likely to describe mentoring relationships as a necessary and important part of their professional lives.

Women valued relationships as part of their service to the university. Senior female faculty members described mentoring as an important contribution to retaining women in engineering (mentoring of both female graduate students and new assistant professors) and talked about how they occasionally expanded their mentoring relationships beyond strict lab training. For instance, one senior female professor recounted a time when another female assistant professor was in her office "distraught," because her husband had left her as a result of being "too focused on work." The older woman shared her own experiences of being left by her first husband for similar reasons and was able to support the younger woman. In these ways, some women academics expand the definitions and responsibilities of mentoring and carry a sense of obligation to support younger women in the field.

This distinction reflects the tendency for female faculty to be sought out by students for unpaid and undervalued emotional labor (Acker and Feuerverger 1996; Bellas 1999). Emotional labor can be taxing for female faculty both in terms of time and their own mental health, and such labor tends to go unacknowledged institutionally, especially when it comes to tenure and promotion decisions. As such, while women consider mentoring relationships as an important measure of success, and bear a disproportionate amount of the associated emotional labor, the undervaluation likely contributes to the lower levels of formal success for women, especially in male-dominated fields (Bellas 1999; Pugliesi 1999).

Suggesting that even younger women tend to extend definitions of mentoring, a female Ph.D. student described mentoring as an opportunity to show younger generations that women can be practicing engineers: if she was the one showing up to STEM expos at grade school, students would see not only that engineers could be women, but that they are women. Related to mentoring, women 
were also more likely to redefine grants as a way to hire, train, and mentor more students (and that as a form of success), as opposed to male engineers who talked about the act of receiving a grant itself as a form of success.

I was here for almost twenty years, and I came from industry, and I did establish a research program, and we were able to get funding on a reasonably regular basis to have a steady group of students coming through the labs, and so I did feel successful in doing that, on a small scale. (Female professor 2)

In our interviews women were more likely to attribute their success to their own mentors as well as supportive family members, which exemplifies another aspect of gender socialization-men are typically more likely to ascribe their accomplishments to their own acumen and aptitude, while women tend to ascribe success to situational factors:

I do have a few people who have, what do I mean, helped me define areas of research, worked on projects with me. My husband is in the same field, so I talk to him a lot, he gives me a lot of good advice. Collaborators, like my advisor, helped me a lot at one point. (Female associate professor 1)

I think it was a couple of things. One, my dad. Two, my major professor. He helped me write my application for the fellowship, because it is an internal grant. (Female Ph.D. candidate 3)

Not so much [mentoring] in grad school ... I guess I can think of a couple people back at the high school level. They sort of have, there aren't particular individuals that I can identify in college or grad school. I mean other than I was always pretty active with my peer group, so I would, as you expect I learned probably more from my peers than I did from faculty. (Male professor 2)

\subsubsection{The Influence of Gendered Stereotypes}

We saw the influence of gender-stereotypes, particularly related to competitiveness and risk-taking, affecting the perceptions engineers held on gender equity and success. Specifically, male engineering academics tend to perceive their female colleagues as less competitive and less likely to take risks, even if they are not.

To varying degrees, both male and female academics and graduates students suggested that men are more competitive in their professional lives than women; and that women tend to avoid conflicts, seek collaborative relationships, and/or are less likely to compare themselves to others when measuring success. These descriptions align with stereotypical gender roles that prescribe assertiveness and drive to men and obedience and passiveness to women.

I think men are generally more competitive as a stereotype, and they compare themselves tremendously and they have to do better than the other person, and women are more satisfied, generally again a stereotype, if they are happy with what they have done and they don't necessarily compare themselves so much to other people which I think maybe a healthier personality profile. But, then again that is totally my bias and subjective thought and a gut instinct as to what it will be. But, I wouldn't be surprised if that was the case, because that's my guess. (Male professor 2)

I would also say that success would be, I mean like, getting along with your colleagues is really important. I don't really like conflict, I would rather talk about a problem in a mature way than it is building up in another way ... I would say having collaborative versus competitive (relationships), because a lot of the time the attitude coming in is I'm in it for myself and I need to do whatever I can to propel my career or make myself have a better 
reputation, you know? And if I can use someone to get there, then that's okay, but I don't think that is okay. (Female Ph.D. candidate 3)

To some male engineering faculty, stereotypical thinking drives their understandings of the gender equity gap in promotion and tenure. One male associate professor mentioned failure as a form of success, stating "you have to be willing to risk things. You have to be willing you fail. We learn more from failing than from succeeding, so I would describe failing as a form of success" (Male associate professor 1).

Contrary to these stereotypical beliefs, recent research on risk taking in academia has not revealed statistically significant gender differences in competitiveness (Sarathchandra 2017). Nonetheless, the perception that women are less likely to take risks still impacts the way female faculty view their own work and how their labor is viewed by their male colleagues. Furthermore, extant research suggests that sex-role stereotypes can negatively influence female success in STEM fields; student perceptions of female faculty members (Kierstead et al. 1988; Miller and Chamberlin 2000); and their treatment by both male and female colleagues (Davison and Burke 1999; Heilman and Parks-Stamm 2007; Heilman and Eagly 2008).

Overall, both men and women in our interviews seem to downplay their own success, which may be a manifestation of the typical academic culture at public universities (and social desirability bias): graduate student enculturation and academic research often equates success to positive outcomes, at least in the long run, but emphasize that successful outcomes are never assured (Delamont and Atkinson 2001, p. 96). As a result, one can posit that students and faculty in academia are more cautious when assessing their success. Add to that the idea that all scientists build on work of those who came prior to them, which potentially further reduces the tendency to attribute one's success solely to oneself. Related to this, one female associate professor told us that she was "somewhat successful ... probably not the most successful one out there."

Beyond above differences in descriptions of relationships and gendered stereotypes, we noticed two additional aspects of women's success in engineering. Both women and men in our interviews (1) alluded to some engineering sub-fields as more conducive to women's success (which could lead to the 'ghettoization' effect discussed below; (Lincoln et al. 2012)); and (2) advocated for 'gender blind' practices of engineering (which could have implications for implementing policies to support women in male-dominated fields). We turn to a discussion of these two factors below.

\section{3. 'Engineering for Women'}

Several of our participants, both men and women, identified certain sub-fields of engineering (e.g., biomedical engineering, environmental engineering, and agricultural engineering) as more conducive to women, or as preferred by women. These perceptions reflect enrollment patterns in STEM fields, where women are present in higher numbers in the life sciences in comparison to other STEM disciplines (Rhoten and Pfirman 2007). Prior research suggests that fields such as environmental engineering tend to attract more women as a result of the higher emphasis women place on social impacts, values, and relevance (Farrell 2002). Consider the below two responses from a female graduate student and a male assistant professor:

But I definitely feel that women are more concerned about the overall system versus men who are concerned about the specific design which is why I feel like a lot more women go into humanitarian engineering because it's much more system based versus fix this one design. (Female Masters student 3)

I think that's why the future direction of our department started going into more biological and biomedical engineering. There's a lot more women interested in that than I see in more traditional agricultural engineering. And so yeah, maybe the field of study is, maybe there's more opportunities that are better suited for women. (Male assistant professor 1) 
While our interviews show both men and women alluding to some sub-fields of engineering as more fitting for women, where women are more likely to be successful (and it may be the case that some women engineers choose to go to certain fields that are seen as better serving society), this general attitude does raise questions about potential 'ghettoization' of women's scientific achievements (Lincoln et al. 2012, p. 10). A term adapted from racial/ethnic segregation, 'ghettoization' has been used to describe consequences of women entering previously male-dominated domains. While Lincoln et al. (2012) applied this concept to professional awards and prizes, we suggest that a similar process may occur within certain sub-fields of engineering (e.g., environmental engineering) where women, overtime, become dominant in the field, but the field itself become less-prestigious and/or lower-paying, such that, success in the said field may not garner much recognition or attention from the larger scientific community.

\subsection{Doing Engineering, Undoing Gender}

While operating in a heavily masculine environment, both men and women seem to deemphasize the role of gender and suggest that work environments be 'blind to gender,' hence, failing to challenge the prevailing gendered culture of academic engineering. Women in our sample exhibited many of the coping strategies previously identified by Powell et al. (2009). As a result, "in 'doing' engineering, women often 'undo' their gender" (Powell et al. 2009). Men in our sample, seem to support this undoing through advocating a 'gender blind' practice of engineering. As Butler (2004) argues, the ways in which women perform their gender to gain male acceptance, especially in male-dominated spaces, may implicitly contribute to this devaluation of 'femaleness.'

As a female, I do not think there is a difference between male and female engineering. We need to basically follow the same steps as everyone else. So there is no such thing as we need more women or we need to give them more opportunities. I just think that everything need to be equal for men and women. And that's actually what makes women more successful, because they feel that they are treated equally. So that's my very personal opinion. But I know that they need to give more opportunities to women because there are simply just not enough women in the field. (Female assistant professor 1)

I advocate for blindness when it comes to gender and race. (Male associate professor 1)

That [gender] is beyond Engineering. (Male professor 2)

Declaring themselves as "engineers not women engineers" is a common attitude that has been observed elsewhere (Powell et al. 2009). 'Distancing' (Rhoton 2011) from 'femaleness' was particularly acute in discussions of gender bias. One female Masters student said that she did not think she had ever been discriminated against, but she could definitely see how it could happen to other women. Some women also engaged in implicit devaluing of their femininity, such as the female Ph.D. candidate below, who seem to have adopted an 'anti-woman' approach, which Powell et al. (2009) described as a rather common coping strategy in engineering:

I was talking to my dad ... and he asked me why I was doing so okay, and I didn't know, and he was like you act like a man. My default is logic and I don't like drama and I feel like females can be so petty so maybe that's it ... Like most of my friends are male and if they are female they are most likely in the STEM fields. So, I don't know if that means anything, but I think it is interesting. (Female Ph.D. candidate 3)

In line with Powell et al. (2009), we also observed other coping strategies employed by women in engineering. These include 'seeing advantages over disadvantages' and 'accepting gender discrimination.' Only one individual in our interviews directly acknowledged gender bias and stereotyping as a systemic issue in STEM fields. One female associate professor recalled her last raise, saying that she and a similarly qualified male professor asked for raises at the same time and were 
given offers by the department. She accepted the first offer, but later found out that the male professor had sent his initial offer back, ending up with a bigger raise. She cited her own ignorance of salary negotiations as the problem.

In anecdotes, we observed several instances of gender stereotyping by male engineers, and less frequently by women too. One male professor stated that he was not discriminatory in his hiring practices, he was blind to gender, but he thought women just would not be interested in his research because it was "gross." Another male student recounted a time when a fellow student, a single mother, had to "put her family first and her research suffered." One female student dismissed another potential interviewee because "she had a baby."

Purported "gender blindness" masks and, in turn, perpetuates the effects of sex-role stereotyping and structural gender inequity. It not only reinforces male-dominated ways of doing as normative, but also systemically limits female success by perpetuating wage inequality (Kray et al. 2002), the motherhood penalty (Cuddy et al. 2004; Correll et al. 2007), and other forms of gender discrimination (Ridgeway 1997; Davison and Burke 1999).

\section{Conclusions}

This study uncovered a number of formal and informal measures of success pertaining to academic engineering. While some of these measures directly affect career progression through graduation, tenure and promotion, others capture elements of the context within which engineering academics operate. This 'dual' nature in accounts of success was common among both male and female engineering students and faculty. While we did not observe much variation in how female and male engineers attributed their success to formal measures, we uncovered gender-based variations in informal measures of success. Specifically, both men and women mentioned the importance of relationships to their success, but in different ways. Women were more likely to be subjected to gender-based stereotypes about perceptions of success. As a consequence, women engineers employed many of the coping strategies that women employees are known to use in male-dominated spaces, such as distancing, advocating for 'gender blind' approaches, and ascribing to 'ghettoization' of some engineering sub-fields.

In some ways, our categorization of formal and informal measures align with two prior studies: (1) Gilbert and Mulkay (1984) work on scientific discourse where scientists employed 'empiricist' terms to describe their own successes and 'contingent' terms to explain away others' failures, and (2) Delamont and Atkinson (2001) study where students accounted for their own initial failures using contingent terms, but described their subsequent successes in empiricist terms. 'Empiricist' terms typically includes beliefs and actions seen as objective, methodologically rigorous, or derived from nature, whereas 'contingent' terms are seen as derived from personal shortcomings, inclinations or self-interest. Somewhat similarly, the 'dual' accounts of success uncovered in our study includes both loosely 'empiricist' (termed "formal" in this paper) and 'contingent' (termed "informal" in this paper) terms, and this is seen throughout the pipeline, from Masters students to tenured faculty, and among both men and women engineers.

There are several potential implications of the dual nature in the accounts of success uncovered in this research. Many institutional measures of success such as publications, citations, patents, and grants, have been noted in prior literature as areas where women already face covert and overt barriers. If women are measuring themselves exclusively by using these measures, unaware of the ways in which they are disadvantaged in these areas, they may perceive themselves as less competent than their male colleagues. This is especially concerning for traditionally male-dominated fields where women have recently begun to achieve significant, yet small, gains. A better awareness of structural factors that shape women's success might be especially pertinent in fields that are male-dominated. This was illuminated in one of our interviews where a female Ph.D. student described how she struggled with feelings of rejection and isolation in her program until she took an introductory sociology class: there she discovered that she was not the only one who felt this way, there was not 
something wrong with her, "there was something wrong with the system." Understanding the systemic and pervasive nature of gender bias in STEM helped her realize that she was "a good engineer in a bad climate."

As a result of seeing masculinity/maleness as the norm (Lemons and Parzinger 2007; Powell et al. 2009), both men and women in engineering may only have access to narratives of success that highlight stereotypically masculine traits (and downplay feminine traits). This could account for the homogeneity in descriptions of success that we encountered, particularly when addressing formal measures. Because there are so few women, and because women have to distance themselves from each other and their femininity, they may not be able to construct or promote inclusive accounts of success or challenge the gendered status quo.

By investigating both formal and informal measures, the present study highlights the context surrounding scientific success. Gender variations in informal measures show that women are at a particular disadvantage. For instance, while women value mentoring relationships and service more than men, the prevailing academic culture generally undervalues these contributions when assessing scientific accomplishments. Additionally, both male and female engineers subscribe to the notion of women engineers fitting some subfields of engineering better than others, which could lead to devaluation of such subfields, further limiting women's success by exacerbating wage differences, motherhood penalty, and the like (Kray et al. 2002; Correll et al. 2007).

Considering that one's self-assessment of success affects their subsequent decisions such as decisions to seek jobs, or apply for tenure and promotion, it is important to understand the variations in women's and men's accounts of success, and account for both formal and informal measures when assessing success. Based on the evidence of the present study, it is reasonable to propose that gender-based stereotypes about what personality traits could lead to success (e.g., competitiveness and risk seeking, that are often associated with masculinity) create barriers for women who enter male-dominated academic domains.

University administrators and policy makers can address these issues by taking into consideration how context shapes perceptions of success. More nuanced approaches to gender equity in male-dominated academic fields would entail supporting and recognizing mentoring relationships, creating mechanisms for equitable distribution of mentoring/service duties, creating positive policies for better work/life balance (e.g., childcare, parental leave), and combating biases in the broader academic culture that tacitly assumes femininity as incongruent with the scientist role. Furthermore, better awareness of how structural and contextual factors shape perceptions and realities of scientific success may help students, faculty, and university administrators to combat potential biases in enrollment, funding, hiring, tenure, promotion, and awards decisions.

Future research should further examine the informal measures participants alluded to in our interviews such as failure, happiness, and quality of life. For instance, perceptions of failure are potentially important to how scientists grapple with unsuccessful research projects. In future research, it would be useful to examine whether engineering academics and students ascribe failure to a lack of personal competence or aspects of the natural world that are beyond the control of the individual scientists. If so, are there gender variations in these ascription patterns? Similarly, future research should examine whether prior institutional (formal) success causes variations in later accounts of success. Are scientists who have already achieved prominence (through large grants, publications, awards, etc.) less likely to allude to the context that surrounded their success?

Future research could benefit from employing survey methodologies to quantify the prevalence of various measures we have uncovered. Such surveys should oversample women in order to account for the low numbers of women in upper academic ranks of engineering. It is also important to recognize that the dichotomous categorization of academic engineers into men and women operate under a broad generalization. As stated by Faulkner (2009, p. 15), "not all men are comfortable in engineering workplace cultures, and not all women are marginalized." While research suggests that the predominantly masculine narratives of success may negatively and disproportionately affect 
women, future research should consider gender with more nuance, accounting for diversity within gender identity.

Acknowledgments: The authors would like to thank Michelle Sing for research assistance during interview data collection phase I. This research was partially supported by a University of Idaho IGEM Grant and a SURF grant.

Author Contributions: Dilshani Sarathchandra and Kristin Haltinner conceptualized the study and oversaw the data collection. Dilshani Sarathchandra, Nicole Lichtenberg and Michelle Sing conducted interviews, and Nicole Lichtenberg and Hailee Tracy transcribed the interviews. Dilshani Sarathchandra and Nicole Lichtenberg analyzed the initial pilot data. Dilshani Sarathchandra and Hailee Tracy analyzed the subsequent data. Dilshani Sarathchandra and Kristin Haltinner wrote the first draft of the manuscript. All authors revised the subsequent drafts.

Conflicts of Interest: The authors declare no conflict of interest. The funding sponsors had no role in the design of the study; in the collection, analyses, or interpretation of data; in the writing of the manuscript, and in the decision to publish the results.

\section{Appendix A}

\section{Semi Structured Interview Guide}

1. What made you decide to go to grad school? (or pursue a higher degree?)

2. What was [is] your research topic for your dissertation/thesis?

3. Were you happy with that work? Were you happy with how it ended?

4. Did you accomplish what you wanted to as a grad student? What were your goals for afterwards?

5. What brought you to this university?

6. What department do you work in?

7. Do you also teach classes?

8. Which do you like better, teaching or research?

9. Do you like the research you are doing currently? Did you choose the research agenda yourself?

10. What are your other research interests?

11. Do you have plans of pursuing them?

12. How much control do you have of your research agenda?

13. Are you pleased with the direction of your current research?

14. Do you think it's been successful?

15. What are some shortfalls?

16. Is research what you envisioned it would be? (as an undergrad, grad, faculty)

17. Did you meet the professional goals you set as a grad student?

18. Did you set other goals that you met or didn't meet?

19. Do you think/know whether your colleagues had similar goals?

20. What do you think are the "typical" goals for your field?

21. What are you personal goals?

22. What were your goals going into research at this university?

23. Why did/do you want to do research?

24. What do you like most about your work?

25. How would you define being successful in your field?

26. Would you say you are a successful scientist? What criteria do you use to determine your level of success?

27. Who or what else would you say has contributed to your success in your field?

28. Is there anything else that might have contributed to your success that we missed? 


\section{References}

Acker, Sandra, and Grace Feuerverger. 1996. Doing Good and Feeling Bad: The Work of Women University Teachers. Cambridge Journal of Education 26: 401-22. [CrossRef]

Bellas, Marcia L. 1999. Emotional Labor in Academia. Annals of the American Academy of Political and Social Science 561: 96-110. [CrossRef]

Beyer, Sylvia. 2015. Women and Science, Technology, Engineering, and Math (STEM). Oxford: Oxford University Press.

Blickenstaff, Jacob Clark. 2005. Women and Science Careers: Leaky Pipeline or Gender Filter? Gender and Education 17: 369-86. [CrossRef]

Butler, Judith. 2004. Undoing Gender. London: Routledge.

Ceci, Stephen J., and Wendy M. Williams. 2011. Understanding Current Causes of Women's Underrepresentation in Science. Proceedings of the National Academy of Sciences USA 108: 3157-62. [CrossRef] [PubMed]

Ceci, Stephen J., Donna K. Ginther, Shulamit Kahn, and Wendy M. Williams. 2014. Women in Academic Science: A Changing Landscape. Psychological Science in the Public Interest 15: 75-141. [CrossRef] [PubMed]

Correll, Shelley J., Stephen Benard, and In Paik. 2007. Getting a Job: Is There a Motherhood Penalty? American Journal of Sociology 112: 1297-338. [CrossRef]

Cuddy, Amy, Susan T. Fiske, and Peter Glick. 2004. When Professionals Become Mothers, Warmth Doesn't Cut Ice. Journal of Social Issues 60: 701-18. [CrossRef]

Davison, Heather K., and Michael J. Burke. 1999. Sex Discrimination in Simulated Employment Contexts: A Meta-analytic Investigation. Journal of Vocational Behavior 56: 225-48. [CrossRef]

Delamont, Sara, and Pauln Atkinson. 2001. Doctoring Uncertainty: Mastering Craft Knowledge. Social Studies of Science 31: 87-107. [CrossRef]

Dryburgh, Heather. 1999. Work Hard, Play Hard: Women and Professionalization in Engineering-Adapting to the Culture. Gender and Society 13: 664-82. [CrossRef]

Erickson, Shelley K. 2012. Women Ph.D. Students in Engineering and a Nuanced Terrain: Avoiding and Revealing Gender. The Review of Higher Education 35: 355-74. [CrossRef]

Etzkowitz, Henry, Carol Kemelgor, and Brian Uzzi. 2000. Athena Unbound: The Advancement of Women in Science and Technology. Cambridge: Cambridge University Press.

Evetts, Julia. 1997. Women and Careers in Engineering: Management Changes in the Work Organization. Women in Management Review 12: 228-33. [CrossRef]

Evetts, Julia. 1998. Managing the Technology but Not the Organization: Women and Career in Engineering. Women in Management Review 13: 283-90. [CrossRef]

Farrell, Elizabeth F. 2002. Engineering a Warmer Welcome for Female Students: The Discipline Tries to Stress its Social Relevance, an Important Factor for Many Women. Chronicle Higher Education (22 February 2002). Available online: https://www.chronicle.com/article/Engineering-a-Warmer-Welcome/30982 (accessed on 2 December 2017).

Faulkner, Wendy. 2009. Doing Gender in Engineering Workplace Cultures. I. Observations from the Field. Engineering Studies 1: 3-18. [CrossRef]

Fox, Mary Frank. 2005. Gender, Family Characteristics, and Publication Productivity among Scientists. Social Studies of Science 35: 131-50. [CrossRef]

Fox, Mary Frank, Mary Lynn Realff, Diana Roldan Rueda, and Jillian Morn. 2016. International Research Collaboration among Women Engineers: Frequency and Perceived Barriers, by Regions. Journal of Technology Transfer. [CrossRef]

Gherardi, Silvia. 1994. The Gender We Think, the Gender We Do in Our Everyday Lives. Human Relations 47: 591-610. [CrossRef]

Gilbert, G. Nigel, and Michael Mulkay. 1984. Opening Pandora's Box: A Sociological Analysis of Scientists' Discourse. Cambridge: Cambridge University Press.

Glover, Judith, Jane Fielding, and Deborah Smeaton. 1996. What Happens to Women and Men with SET Degrees? Labour Market Trends 104: 63-67. 
Heilman, Madeline E., and Alice H. Eagly. 2008. Gender Stereotypes Are Alive, Well, and Busy Producing Workplace Discrimination. Industrial and Organizational Psychology 1: 393-98. [CrossRef]

Heilman, Madeline E., and Elizabeth J. Parks-Stamm. 2007. Gender Stereotypes in the Workplace: Obstacles to Women's Career Progress. In Social Psychology of Gender. Edited by Correll, Shelley J. Bingley: Emerald Group Publishing Limited, pp. 47-77.

Keller, Evelyn Fox. 1985. Reflections on Gender and Science. New Haven: Yale University Press.

Kierstead, Diane, Patti D'agostino, and Heidi Dill. 1988. Sex role stereotyping of college professors. Journal of Educational Psychology 80: 342-44. [CrossRef]

Kray, Laura J., Adam D. Galinsky, and Leigh Thompson. 2002. Reversing the Gender Gap in Negotiations: An Exploration of Stereotype Regeneration. Organizational Behavior and Human Decision Processes 87: 386-409. [CrossRef]

Latour, Bruno. 1987. Science in Action. Cambridge: Harvard University Press.

Leahey, Erin. 2007. Not by Productivity Alone: How Visibility and Specialization Contribute to Academic Earnings. American Sociological Review 72: 533-61. [CrossRef]

Leahey, Erin, and Cindy L. Cain. 2013. Straight from the Source: Accounting for Scientific Success. Social Studies of Science 43: 927-51. [CrossRef]

Lemons, Mary A., and Monica Parzinger. 2007. A Cognitive Explanation of Discrimination of Women in Technology. Journal of Business and Psychology 22: 91-98. [CrossRef]

Lincoln, Anne E., Stephanie Pincus, Janet Bandows Koster, and Phoebe S. Leboy. 2012. The Matilda Effect in Science: Awards and Prizes. Social Studies of Science 42: 307-20. [CrossRef] [PubMed]

Link, Albert N., Christopher A. Swann, and Barry Bozeman. 2008. A Time Allocation Study of University Faculty. Economics of Education Review 27: 363-74. [CrossRef]

Long, J. Scott. 1990. The Origins of Sex Differences in Science. Social Forces 68: 1297-316. [CrossRef]

Long, J. Scott, Paul D. Allison, and Robert McGinnis. 1993. Rank Advancement in Academic Careers: Sex Differences and the Effects of Productivity. American Sociological Review 58: 703-22. [CrossRef]

McDowell, George R. 2003. Engaged Universities: Lessons from the Land-Grant Universities and Extension. The ANNALS of the American Academy of Political and Social Science 585: 31-50. [CrossRef]

Miller, JoAnn, and Marilyn Chamberlin. 2000. Women are Teachers, Men are Professors. Teaching Sociology 28: 283-98. [CrossRef]

Powell, Abigail, Barbara Bagilhole, and Andrew Dainty. 2009. How Women Engineers Do and Undo Gender: Consequences for Gender Equality. Gender, Work and Organization 16: 411-28. [CrossRef]

Pugliesi, Karen. 1999. The Consequences of Emotional Labor. Motivation and Emotion 23: 125-54. [CrossRef]

Rhoten, Diana, and Stephanie Pfirman. 2007. Women in Interdisciplinary Science: Exploring Preferences and Consequences. Research Policy 36: 56-75. [CrossRef]

Rhoton, Laura A. 2011. Distancing as a Gendered Barrier: Understanding Women Scientists' Gender Practices. Gender and Society 25: 696-716. [CrossRef]

Ridgeway, Cecilia L. 1997. Interaction and the Conservation of Gender Inequality: Considering Employment. American Sociological Review 62: 218-35. [CrossRef]

Sarathchandra, Dilshani. 2017. Risky Science? Perception \& Negotiation of Risk in University Bioscience. Bulletin of Science, Technology, and Society. [CrossRef]

Schuh, G. Edward. 1986. Revitalizing Land Grant Universities: It's Time to Regain Relevance. Choices 1: 6-10.

Silverman, David. 2004. Qualitative Research: Theory, Method and Practice. Thousand Oaks: Sage.

Tao, Yu, Wei Hong, and Ying Ma. 2017. Gender Differences in Publication Productivity among Academic Scientists and Engineers in the U.S. and China: Similarities and Differences. Minerva 55: 459-84. [CrossRef]

Widnall, Sheila E. 1988. AAAS Presidential Lecture: Voices from the Pipeline. Science 241: 1740-45. [CrossRef] [PubMed]

Xie, Yu, and Alexandra Killewald. 2012. Is American Science in Decline? Cambridge: Harvard University Press.

Xie, Yu, and Kimberlee A. Shauman. 1998. Sex Differences in Research Productivity: New Evidence about an Old Puzzle. American Sociological Review 63: 847-70. [CrossRef] 
Xie, Yu, and Kimberlee A. Shauman. 2003. Women in Science: Career Processes and Outcomes. Cambridge: Harvard University Press.

Yoder, Brian L. 2017. Engineering by the Numbers. American Society for Engineering Education. Available online: https: / /www.asee.org/papers-and-publications/publications/college-profiles/15EngineeringbytheNumbersPart1.pdf (accessed on 2 December 2017). 